http://doi.org/10.48195/sepe2021-029

\title{
PANDEMIA E ESTRATÉGIAS DE COPING UTILIZADAS POR MÃES DE CRIANÇAS COM TRANSTORNO DO ESPECTRO AUTISTA
}

\author{
Pâmela Schultz Danzmann'; Luciane Najar Smeha²
}

\section{RESUMO}

Objetiva-se conhecer quais são as principais estratégias de coping utilizadas pelas mães de crianças com Transtorno do Espectro Autista(TEA), tendo vista dois tipos de coping, o focado na emoção e o focado no problema. Trata-se de uma uma revisão integrativa da literatura que ocorreu nos meses de maio a agosto de 2021. A busca de publicações foi realizada nas plataformas Google Acadêmico e plataforma Scielo. As principais estratégias de cooping focadas no problema foram: mudar ou aproximar a rotina da criança com a anterior ao período da pandemia, conversar com a criança sobre o que está acontecendo no mundo, fornecer informações sobre distanciamento físico e higienização das mãos. Já as estratégias focadas na emoção são a religiosidade e conversar com alguém próximo. Conclui-se que existem inúmeras formas de lidar com o estresse, elas podem ser focadas no problema, na emoção ou em ambas, isso dependerá de cada mãe.

Palavras-chave: Autismo; Coping; Maternidade.

Eixo Temático: Atenção Integral e Promoção à Saúde (AIPS)

\section{INTRODUÇÃO}

A palavra "autismo" foi utilizada pela primeira vez no ano de 1911, associada a perda de contato com a realidade e somada às dificuldades de comunicação (GADIA; TUCHMAN; ROTTA, 2004). Em 1940, um psiquiatra infantil chamado Leo Kanner publicou um documento onde se referia a um novo tipo de autismo que denominou, autismo infantil (WHITMANN, 2015). Já em 1944, Hans Asperger percebeu características autistas em pessoas que apresentavam uma inteligência dentro dos parâmetros considerados "normais", todavia, esses indivíduos tinham uma enorme dificuldade de socialização (BERNAL, 2018; GADIA; TUCHMAN; ROTTA, 2004). Embora Kanner seja reconhecido na literatura nacional e internacional por abordar a temática do autismo, também é criticado por ter

\footnotetext{
${ }^{1}$ Autor/Apresentador : Universidade Franciscana- UFN. pamelapsicologia10@gmail.com

${ }^{2}$ Professora Orientadora: Universidade Franciscana- UFN. lucianeanenajar@yahoo.com.br
} 
considerado o transtorno como uma resposta da criança à falta de afetividade materna (LIMA, 2014; WHITMANN, 2015). Devido a essa posição até hoje, mães de crianças com Transtorno de Espectro Autista (TEA) são responsabilizadas pelo diagnóstico do(a) filho(a) (GAIATO, 2019; LIMA, 2014; LOPES, 2019).

O Transtorno do Espectro Autista é um distúrbio de desenvolvimento complexo que sofreu algumas modificações durante o passar dos anos (BERNAL 2018). Atualmente, pode ser caracterizado pelos comportamentos repetitivos, dificuldade de socialização e comunicação (APA, 2014).

A pandemia do COVID- 19 teve início no final do ano de 2019 e o primeiro caso de morte registrado foi na China. Desde então a rotina das famílias se modificou. Ademais, o contexto de pandemia pode ter dificultado o fechamento do diagnóstico de muitas famílias. Bem como implicado na interrupção das terapias, inclusão social e convivência familiar daquelas crianças que já haviam sido diagnosticadas e estavam em processo de tratamento (FERNANDES; SPERENZA; MAZAC; GASPARINI; CID, 2021). Ademais, o medo do(a) filha(a) ficar doente, o isolamento social, a dificuldades das crianças em adotarem uma nova rotina podem ser as principais causas do estresse e do cansaço materno.

Diante do estresse, as mães precisam de esforços comportamentais e cognitivos no manejo dessas novas demandas externas e/ou internas. Esse processo denomina-se coping, e pode ser classificado de duas formas: centrado na emoção e centrado na emoção. O primeiro diz respeito à capacidade da mãe em resolver os problemas e achar alternativas para minimizar o evento estressor. Já o coping centrado na emoção tem o objetivo de diminuir sentimentos negativos advindos do estresse (ANTONIAZZI; DELL'AGLIO; BANDEIRA,1988). Objetiva-se conhecer quais são as principais estratégias de coping utilizadas pelas mães de crianças com Transtorno do Espectro Autista, tendo vista dois tipos de coping, o focado na emoção e o focado no problema.

\section{METODOLOGIA}


Trata-se de uma uma revisão integrativa da literatura, que objetiva sintetizar e analisar dados de uma pesquisa de forma sistemática, ordenada e abrangente, fornecendo informações sobre um assunto (ERCOLE; MELO; ALCOFORADO, 2014). As etapas que conduziram à revisão foram: formulação do problema; coleta de dados; avaliação dos resultados encontrados; análise e interpretação dos achados; apresentação dos resultados, discussões (SILVA et al., 2020)

A pergunta norteadora deste estudo é: Quais as estratégias de coping focado nas emoções e na resolução de problemas das mães de crianças diagnosticadas com autismo no contexto da pandemia? Para responder a pergunta, na análise do material encontrado, utilizou-se os seguintes critérios de inclusão: artigos nacionais publicados no ano de 2020 a 2021 , que versam sobre a temática no contexto atual independente do tipo de método utilizado pelo autor. Já os critérios de exclusão foram: artigos que não respondessem a pergunta norteadora e que fugissem do tema escolhido, assim como monografias, teses, dissertações. Além daqueles documentos que não respeitassem o recorte temporal estabelecido.

A revisão integrativa ocorreu nos meses de maio a agosto de 2021 , nas plataformas Google Acadêmico e na plataforma Scielo. Para encontrar os estudos foram utilizados os seguintes descritores: Maternidade; Autismo; Coping , foi realizado o cruzamento simultâneo dos descritores utilizando o booleano "AND" (E) entre eles.

\section{RESULTADOS E DISCUSSÕES}

A pesquisa apontou 27 documentos, destes 14 foram selecionados pelo título para serem lidos na íntegra. A amostra final para a construção desse artigo foi de 5 artigos, que além de responder aos critérios de inclusão, estavam relacionados com o objetivo da pesquisa. O quadro abaixo traz as principais informações correspondentes à amostra total.

Quadro 1: Síntese dos principais resultados encontrados na revisão integrativa:

\begin{tabular}{|l|l|l|l|l|}
\hline Autor/Ano & Título & Periódico & $\begin{array}{l}\text { Base de } \\
\text { dados }\end{array}$ & $\begin{array}{l}\text { Tipo } \\
\text { estudo }\end{array}$ \\
\hline
\end{tabular}




\begin{tabular}{|c|c|c|c|c|}
\hline $\begin{array}{l}\text { ANJOS; } \\
\text { MORAES, } \\
2021 .\end{array}$ & $\begin{array}{c}\text { As } \\
\text { experiências } \\
\text { de famílias } \\
\text { com filhos } \\
\text { autistas: uma } \\
\text { revisão } \\
\text { integrativa da } \\
\text { literatura }\end{array}$ & $\begin{array}{l}\text { Ciências } \\
\text { Psicológicas }\end{array}$ & Scielo & $\begin{array}{l}\text { Revisão } \\
\text { Integrativa }\end{array}$ \\
\hline $\begin{array}{l}\text { FORTES; } \\
\text { MACHADO, } \\
2020 .\end{array}$ & $\begin{array}{c}\text { Análise } \\
\text { comparativa } \\
\text { entre a saúde } \\
\text { mental de } \\
\text { responsáveis } \\
\text { por } \\
\text { pessoas com } \\
\text { TEA e por } \\
\text { crianças sem } \\
\text { TEA na } \\
\text { pandemia de } \\
\text { COVID-19 }\end{array}$ & $\begin{array}{l}\text { Residência } \\
\text { Pediátrica }\end{array}$ & $\begin{array}{l}\text { Google } \\
\text { Acadêmico }\end{array}$ & $\begin{array}{l}\text { Pesquisa de } \\
\text { campo }\end{array}$ \\
\hline $\begin{array}{l}\text { FILGUEIRA; } \\
\text { BRILHANTE, } \\
2021 .\end{array}$ & $\begin{array}{l}\text { Percepção } \\
\text { de mães de } \\
\text { crianças } \\
\text { autistas } \\
\text { sobre o } \\
\text { isolamento } \\
\text { social } \\
\text { motivado } \\
\text { pela } \\
\text { pandemia } \\
\text { do Covid-19 }\end{array}$ & $\begin{array}{l}\text { Investigação } \\
\text { Qualitativa em } \\
\text { Saúde: } \\
\text { Avanços } \\
\text { Desafios }\end{array}$ & $\begin{array}{l}\text { Google } \\
\text { Acadêmico }\end{array}$ & $\begin{array}{l}\text { Pesquisa de } \\
\text { campo }\end{array}$ \\
\hline $\begin{array}{l}\text { LIMA; } \\
\text { VELOSO; } \\
\text { PIMENTA, } \\
2021 .\end{array}$ & $\begin{array}{l}\text { Estratégias de } \\
\text { coping para o } \\
\text { autismo diante } \\
\text { dos novos } \\
\text { desafios } \\
\text { impostos pela }\end{array}$ & $\begin{array}{l}\text { Ciências } \\
\text { Psicológica }\end{array}$ & Scielo & $\begin{array}{l}\text { Pesquisa de } \\
\text { campo }\end{array}$ \\
\hline
\end{tabular}




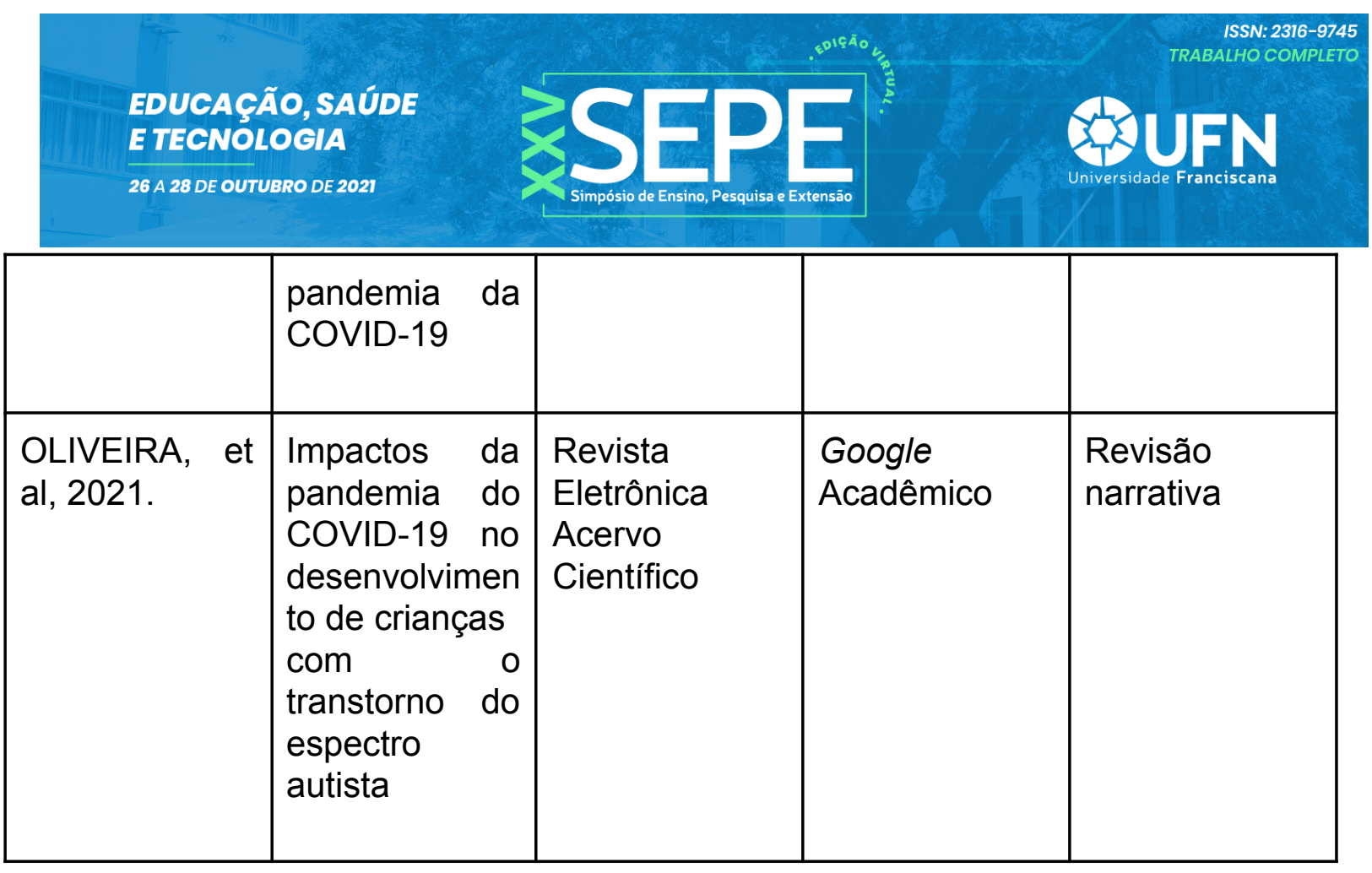

\subsection{ESTRATÉGIAS FOCADAS NO PROBLEMA}

Os principais motivos de estresse das mães desta pesquisa são a rotina da criança que foi desorganizado durante a pandemia e a compreensão da criança diante das mudanças impostas pelo período de isolamento físico. Nesse sentido, as principais estratégias de coping dessas mulheres foram: mudar ou aproximar a rotina da criança com aquela antes do período da pandemia; conversar com a criança sobre o que está acontecendo no mundo; fornecer informações simples sobre distanciamento físico e higienização das mãos.

Devido à alta disseminação do COVID-19 no mundo foi imposto medidas restritivas, com a finalidade de reduzir o contato interpessoal(OLIVEIRA, 2020). Encontrar a forma adequada para explicar à criança com TEA o atual momento de crise sanitária pode ser extremamente difícil a depender do seu nível de compreensão. Por conta disso, algumas instituições criaram guias com o objetivo de relatar de forma lúdica e de fácil compreensão a situação global e a importância da lavagem correta das mãos e distanciamento social (REICHER, 2020).

Além disso, crianças com TEA mostram-se vulneráveis às mudanças de rotina, tais como aulas suspensas, consultórios psicológicos fechados, caminhadas ou exercícios ao ar livre impossibilitados temporariamente, bem como a utilização de 
máscaras ao sair de casa. Tudo isso representou um desafio para crianças com TEA e suas mães, porque diante dessa realidade seus filhos podem demonstrar mais irritabilidade, inquietação e dificuldade de concentração (OLIVEIRA et al, 2020). As mães juntamente com as crianças acabam se estressando muito, nesse sentido, é fundamental considerar estratégias mais adaptativas com a finalidade de mudar a situação geradora de estresse.

\subsection{ESTRATÉGIAS FOCADAS NA EMOÇÃO}

Nessa categoria pode-se observar que os principais motivos de estresse das mães são a falta de uma rede de apoio e a dificuldade de resiliência. As principais estratégias focadas na emoção são a religiosidade; conversar com alguém próximo sobre o que sente. A rede de apoio no contexto materno nasce das necessidades de ajuda da mulher e pode ser formada pela família, amigos, padrinhos das crianças ou quaisquer pessoas que a mãe confie. O fato é que não é fácil construir essa rede, principalmente nos casos de mães com filhos diagnosticados com TEA, devido às características do transtorno e até pelo preconceito social (GAIATO, 2019).

Posto isso, uma das formas das mães lidarem com essa situação que causa tristeza e desamparo é conversar com alguém. No cenário da pandemia, o pai da criança pode ser a única rede de apoio e com quem a mãe consegue desabafar suas angústias (FILGUEIRA; BRILHANTE, 2020).

A capacidade de resiliência diz respeito à forma de adaptação das mudanças ou de resistir à pressão de situações adversas. O contexto da pandemia exige dessa capacidade devido o isolamento social e todas mudanças que isso implica. No contexto familiar com autismo, é compreendida como a superação das adversidades e o entendimento disto como uma oportunidade para o crescimento pessoal (ANJOS; MORAES, 2021). Contudo, diante da realidade atual as mães têm-se mostrado menos resilientes e uma forma de superar isso é a espiritualidade. Diante disso, o suporte suporte espiritual consiste em uma estratégia para lidar com as frustrações diárias (FILGUEIRA; BRILHANTE, 2020). 


\section{QUFN}

\section{CONCLUSÃO}

Conclui-se que existem inúmeras estratégias de coping utilizadas pelas mães de crianças diagnosticadas com TEA. As mães desta pesquisa utilizam as seguintes estratégias focadas no problema: mudar ou aproximar a rotina da criança com aquela antes do período da pandemia, conversar com a criança sobre o que está acontecendo no mundo, fornecer informações simples sobre distanciamento físico e higienização das mãos. Nesse caso os principais estressores foram a rotina desorganizada da criança e a dificuldade materna de repassar para a criança as mudanças devido ao cenário pandêmico.

No que concerne às estratégias de coping focado na emoção os principais motivos de estresse das mães são a falta de uma rede de apoio e a dificuldade de resiliência. Assim essas mães buscam a religiosidade e o diálogo para minimizar a tristeza, a angústia e as dificuldades da maternidade na pandemia.

Ainda são poucas as pesquisas que discutem a maternidade em tempos pandêmico, por isso sugere-se que mais pesquisas sejam realizadas, inclusive no campo da paternidade, 'principalmente ao pensar que em tempos tão incertos muitas famílias perderam os empregos e no cenário brasileiro, muitas vezes é o pai o principal provedor da família.

\section{REFERÊNCIAS}

ANJOS, B. B. dos.; ARAÚJO M. de, N. As experiências de famílias com filhos autistas: uma revisão integrativa da literatura. Cienc. Psicol, v. 15, n. 1, e2347. 2021. Acesso em: 24 ago. 2021.

ANTONIAZZI, A. S.; DELL AGLIO.; D. D., Bandeira, D. R. O conceito de coping: Uma revisão teórica. Estudos de Psicologia, v.3, n.2, p. 273-294, 1998. 24 ago. 2021. 
ASSOCIAÇÃO AMERICANA DE PSICOLOGIA [APA]. Manual diagnóstico e estatístico de Transtornos mentais: DSM-V (5a ed.). Porto Alegre, RS: Artmed, 2014.

BERNAL, M. P. Praxia da criança com Transtorno do Espectro Autista: um estudo comparativo. Tese de Doutorado em Ciências. Instituto de Psicologia, Universidade de São Paulo :São Paulo, 2018. Acesso em: 24 ago. 2021.

HERPES, N. E.; DAPRA, L. R. Crianças com autismo, família e espiritualidade. Revista Semestral de Teologia e Ciência das religiões, v.10, n.15, p.1-22, 2016. Acesso em: 24 ago. 2021.

ERCOLE, F. F.; MELO, L. S. de.; ALCOFORADO, C. G. L. C. Revisão Integrativa versus Revisão Sistemática. Rev Mineira de Enfermagem, v.18, n.1, p. 1-11, 2014. Acesso em: 24 ago. 2021.

FERNANDES, A. D. S. A.; SPERENZA, M.; MAZAC, M. S. R.; GASPARINI, D. A. G; CID, M. F. B. Desafios cotidianos e possibilidades de cuidado com crianças e adolescentes com Transtorno do Espectro Autista (TEA) frente à COVID-19. Cadernos Brasileiros de Terapia Ocupacional, v. 29, e2121, p.1-12, 2021. Acesso em: 24 ago. 2021.

FORTES, C. P. de. C.; MACHADO, L. de. C. Análise comparativa entre a saúde mental de responsáveis por pessoas com TEA e por crianças sem TEA na pandemia de COVID-19. Residência pediátrica, p. 1-2, 2020. Acesso em: 24 ago. 2021.

GADIA, C.A; TUCHMAN, R.; ROTTA, N. T. Autismo e doenças invasivas de desenvolvimento. Jornal da Pediatria, n. 80, v. 2, p. 83-94, 2004. Acesso em: 24 ago. 2021. 
GAIATO, M. Sos autismo, 3 ed. Editora nversos, 2019.

FILGUEIRA, L. M. de.; A. BRILHANTE, A. V. M. Percepção de mães de crianças autistas sobre $\mathrm{o}$ isolamento social motivado pela pandemia do Covid-19. New Trends in Qualitative Research, [S. I.], v. 8, p. 514-520, 2021. Acesso em: 24 ago. 2021.

LIMA, R. C. A. Construção Histórica do Autismo (1943-1983). Ciências Humanas e Sociais em Revista, n.36, v.1, p.109-123, 2014. Acesso em: 24 ago. 2021.

LIMA, C. V. M.; VELOSO, J. C. da S.; PIMENTA, A. da S. Estratégias de coping para o autismo diante dos novos desafios impostos pela pandemia da covid-19. Congresso Internacional em Saúde, v.2, p. 1-2, 2021. Acesso em: 24 ago. 2021.

REICHER, D. Debate: Remote learning during COVID-19 for children with high functioning autism spectrum disorder. Child and Adolescent Mental Health, v. 25, n.4, p.263-364, 2020. Acesso em: 24 ago. 2021.

SILVA, C. C.; SAVIAN, C. M.; PREVEDELlO, B. P.; ZAMBERLAN, C.; DALPIAN, D. M.; SANTOS, B. $Z$ dos. Access and use of dental services by pregnant women: an integrative literature review. Ciênc. Saúde Coletiva, n.25,v.3, p. 827-35, 2020. Acesso em: 24 ago. 2021.

OLIVEIRA, W. K, et al. Como o Brasil pode deter a COVID-19. Revista Epidemiologia e Serviços de Saúde, v.29, n.2, p. 1-7, 2020. 
OLIVEIRA, A. de.; SILVEIRA, I. G.; MORTEI, S. B.; CHAGAS, J. M. de A.; MARTINS, J. T.; GONÇALVES, M. A. C.; PEREIRA, M. L. P. de C.; SANTOS, P. S. dos; BORTOLIT. S.; CORRÊ, AM. I. Impactos da pandemia do COVID-19 no desenvolvimento de crianças com o transtorno do espectro autista. Revista Eletrônica Acervo Científico, v. 27, p. e7728, 2021. Acesso em: 24 ago. 2021.

WHITMANN, T. O desenvolvimento do autismo: Social, cognitivo, linguistico, sensório motor e perspectivas biológicas. $1^{\text {a }}$ ed, M.books, 2015. 